\title{
Observation of regional air pollutant transport between the megacity Beijing and the North China Plain
}

Yingruo $\mathrm{Li}^{1}$, Chunxiang $\mathrm{Ye}^{1,2}$, Jun $\mathrm{Liu}^{1}$, Yi $\mathrm{Zhu}^{1}$, Junxia Wang ${ }^{1}$, Zhiqiang $\operatorname{Tan}^{1}$, Weili $\mathrm{Lin}^{3}$, Limin Zeng $^{1}$, Tong Zhu ${ }^{1,4^{*}}$

${ }^{1}$ State Key Laboratory of Environmental Simulation and Pollution Control, College of Environmental Sciences and Engineering, Peking University, Beijing, 100871, China

${ }^{2}$ Now at School of Chemistry, University of Leeds, Leeds LS2 9JT, UK

${ }^{3}$ Meteorological Observation Center, China Meteorological Administration, Beijing, 100081, China

${ }^{4}$ The Beijing Innovation Center for Engineering Science and Advanced Technology, Peking University, Beijing, 100871, China

*Corresponding Author: tzhu@pku.edu.cn 


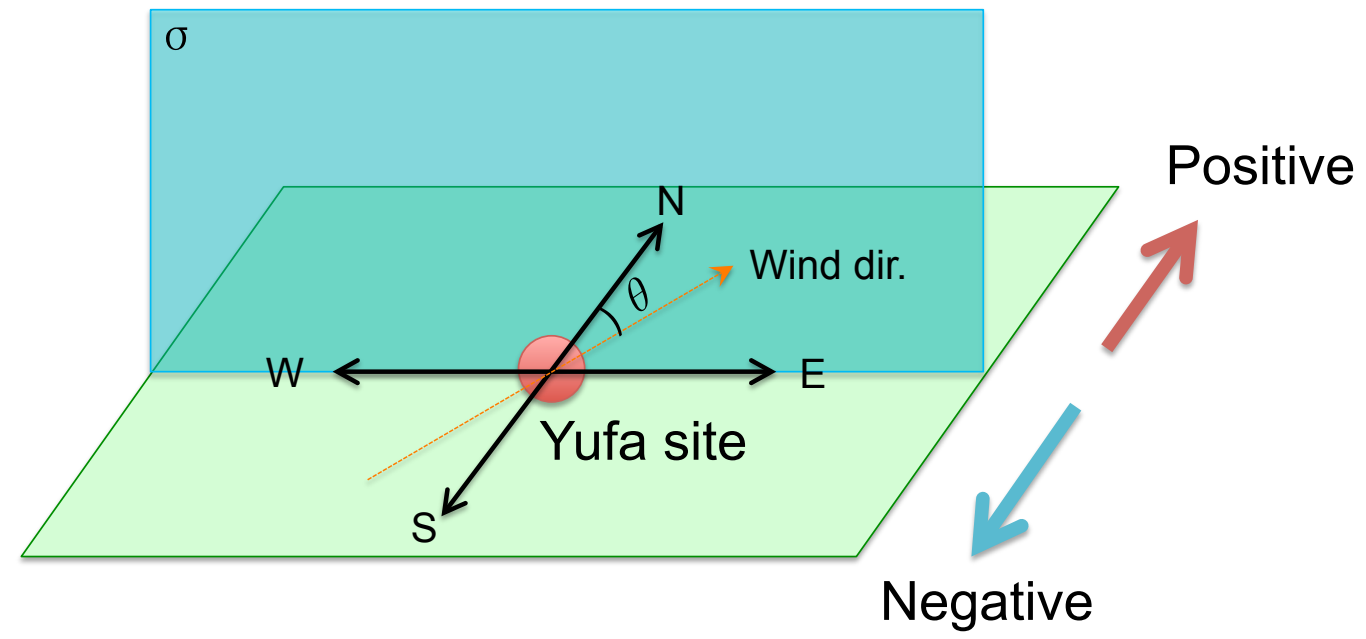

Figure S1. Principles for calculating gaseous pollutant fluxes: the wind vector along the northsouth direction multiplies concentration of gaseous pollutant equals the gas pollutant flux. The direction from south to north (i.e. from the NCP to Beijing) is defined as positive, and vice versa. 

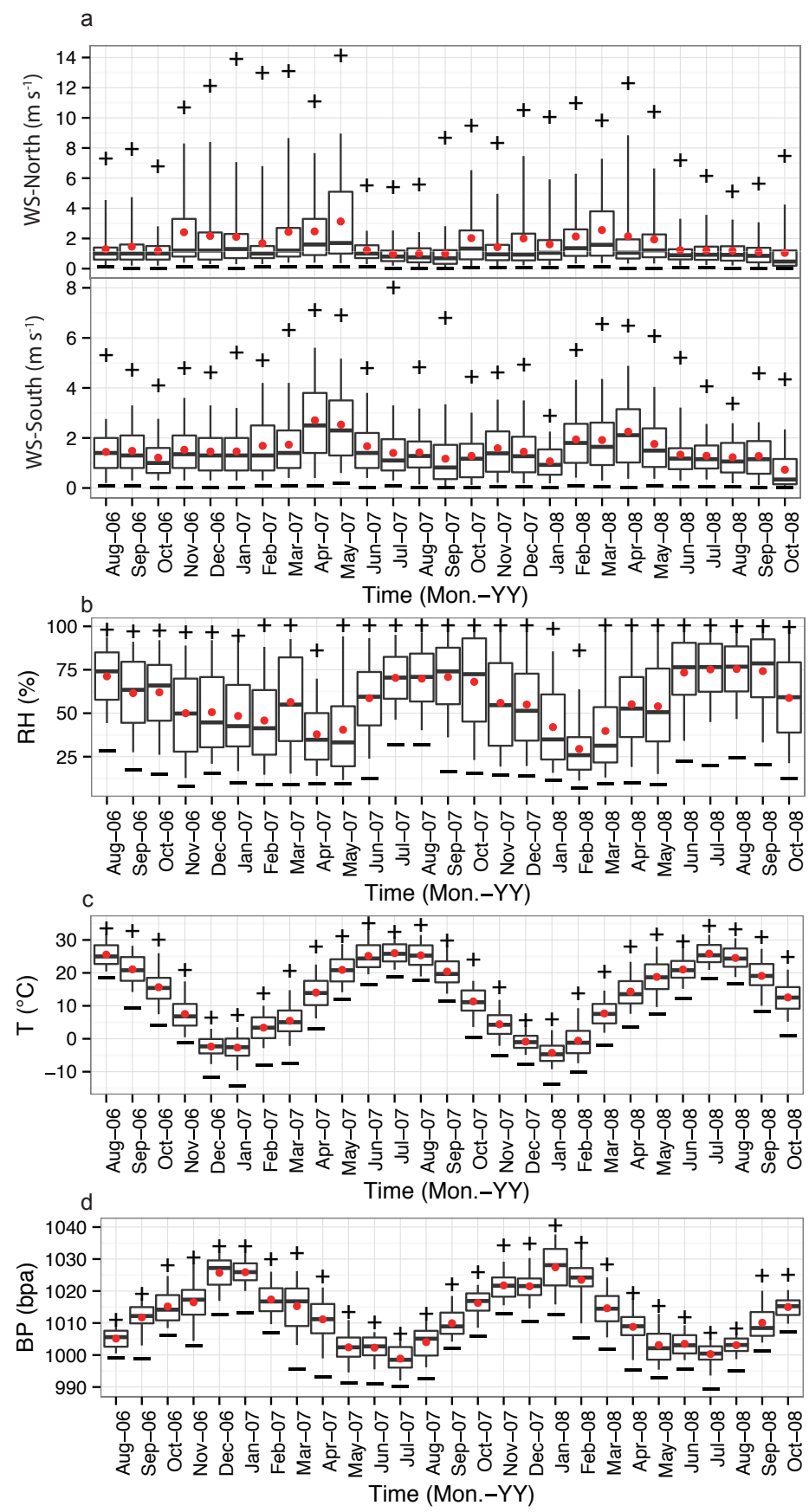

Figure S2. Monthly statistics of wind speed (WS) for north wind (a) top and south wind (a) bottom, relative Humidity $(\mathrm{RH})(\mathrm{b})$, temperature (T) (c) and barometric pressure (BP) (d) at the Yufa site. The red point represents the mean value. The black cross bar stands for the median value. The black box and whisker denote the 5th, 25th, 75th and 95th percentiles, respectively. The plus and minus symbols represent the maximum and minimum, respectively. 


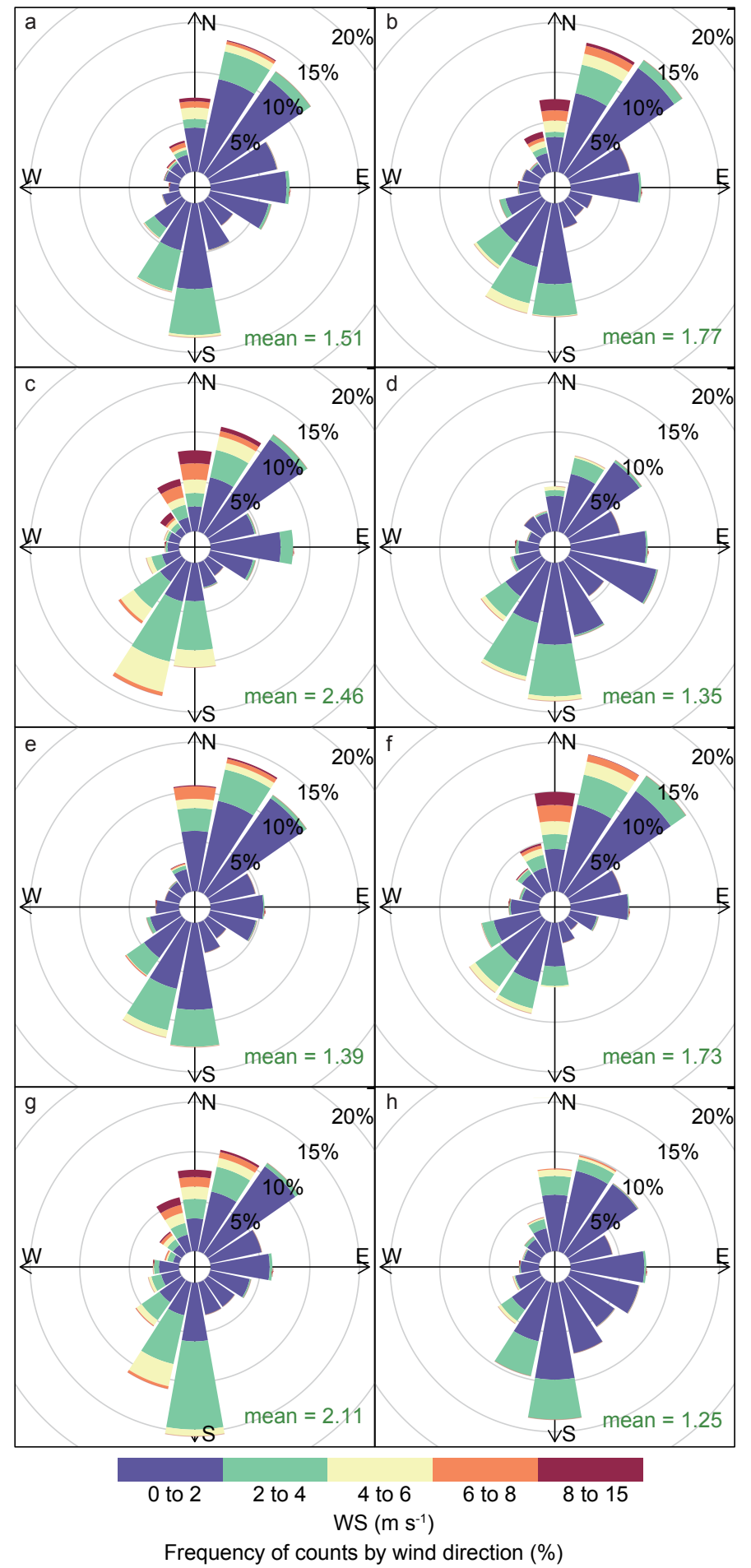

Figure S3. Wind rose plots based on frequencies of hourly data in autumn of 2006 (a), winter of 2006 (b), spring of 2007 (c), summer of 2007 (d), autumn of 2007 (e), winter of 2007 (f), spring of $2008(\mathrm{~g})$, and summer of $2008(\mathrm{~h})$ at the Yufa site. 

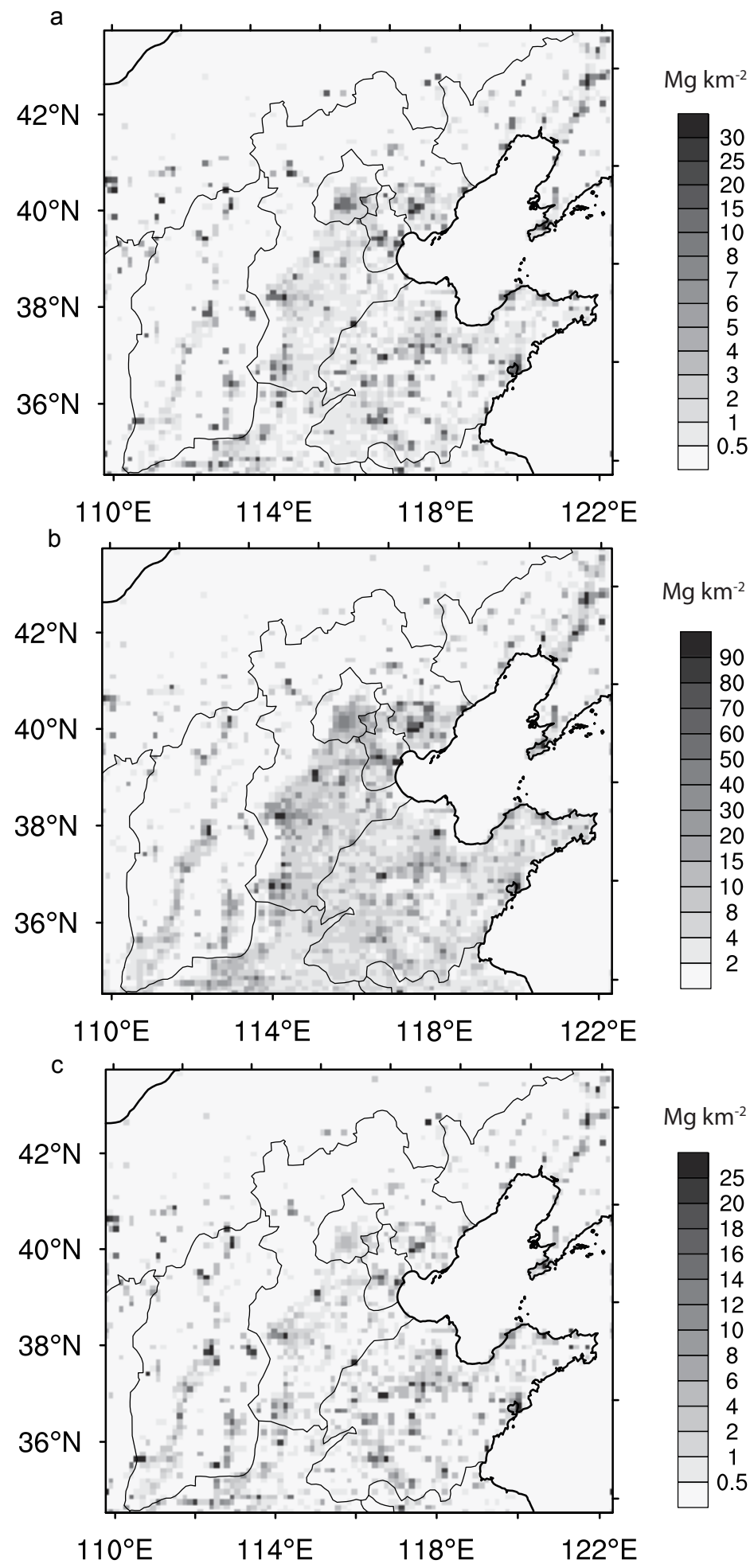
Figure S4. The emission inventory map of $\mathrm{NO}_{x}(\mathrm{a}), \mathrm{CO}(\mathrm{b})$, and $\mathrm{SO}_{2}(\mathrm{c})$ based on the statistic data of Zhang et al. (2009).

\section{References}

Zhang, Q., D. G. Streets, G. R. Carmichael, K. B. He, H. Huo, A. Kannari, Z. Klimont, I. S. Park, S. Reddy, J. S. Fu, D. Chen, L. Duan, Y. Lei, L. T. Wang and Z. L. Yao. Asian emissions in 2006 for the NASA INTEX-B mission. Atmos. Chem. Phys., 9, 5131-5153, doi:10.5194/acp-9-51312009 